\title{
16. MANAGEMENT SYSTEM FOR TELECOMMUNICATIONS ENGINEER TRAINING
}

\author{
Yasuo Minai \\ Masayuki Yamauchi \\ Human Resource Development Center, \\ Telecommunications Division, Hitachi, Ltd. \\ 216 Totsuka-cho, Totsuka-ku, \\ Yokohama 244-8567, Japan \\ e-mail: yasuo_minai@cm.tcd.hitachi.co.jp \\ masayuki_yamauchi@cm.tcd.hitachi.co.jp \\ Tsurayuki Kado \\ Information Systems Group, Hitachi, Ltd. \\ 6-27-18 Minami-Oi, Shinagawa-ku, \\ Tokyo 140-8572, Japan \\ e-mail: t-kado@comp.hitachi.co.jp
}

\begin{abstract}
This paper introduces an example of engineer training conducted in a factory where telecommunication systems and related products are developed and manufactured. About 1,400 engineers are being trained. There are seven specialty categories according to the types of duties of the engineers. Guidelines are prepared for these engineering specialty categories to promote well-planned training of engineers. The guidelines are posted on the factory's intranet to invite trainees and to accept their applications.
\end{abstract}

The training management system stores the individual engineer's training history and future plans in a database based on the trainee's program. A person in charge is assigned to each engineering category to systematically establish new training courses, close obsolete courses, integrate courses, or improve a course's curriculum.

\section{Keywords}

Educational management, database, Internet, learning systems, special needs

The original version of this chapter was revised: The copyright line was incorrect. This has been corrected. The Erratum to this chapter is available at DOI: 10.1007/978-0-387-35393-7_22 


\section{Introduction}

The field of telecommunications is in the midst of a great revolution and competition on a global scale due to the rapid development of digitization, as well as borderless and inter-industry competition. It has become more important than ever to provide engineers with training in the basics as well as in the latest technology in the industry to develop, manufacture and sell telecommunications products that satisfy the market needs 1 .

This paper introduces the management system for the engineering personnel working in Hitachi's telecommunications factory.

\section{Types of Engineers and Training Subjects}

The factory the authors are associated with develops and manufactures telecommunications products including central office switching systems and transmission equipment for common carriers, PBXs, multiplexers, and communication terminals for composing corporate networks. Table 1 lists the engineers working in the factory categorized by specialties. Approximately 1,400 of those engineers are taking training.

Customer system engineers (SEs) include the pre-system engineer who proposes a system to meet the customer's requirements that are identified through reviews with the customer, and the post-system engineer who develops and designs the system and its equipment [components]. The actual equipment design engineering requires a hardware design engineer who designs the circuit hardware, a device and packaging engineer who performs physical design engineering, and a software design engineer. A production engineer is needed to put a design into a product. Finally, the quality assurance (QA) engineer is also required to inspect the products and assure their quality in order to place highly reliable products on the market.

The engineer training concerns of the factory are summarized as follows:

1. A single-purpose training course cannot attain all desired results, since the specialties required for individual engineers vary widely.

2. The engineering ability of engineers in the same specialty varies with their experience.

3. It is essential to be able to dynamically cancel old training subjects and establish new training subjects to keep the training courses up-to-date. 
Table 1 Engineer Specialties

\begin{tabular}{ll}
\multicolumn{1}{c}{ Specialty } & Description \\
\hline (1) Customer SE & Pre-SE \\
(2) System & Post-SE and equipment design and development \\
(3) Hardware & Hardware and circuit design \\
(4) Device and packaging & Packaging and construction design \\
(5) Software & Software design \\
(6) Production engineering & Production engineering \\
(7) QA & Inspection and quality assurance
\end{tabular}

\section{Overview of Engineer Training}

\subsection{Engineer Training Courses and Guideline}

Table 2 lists a summary by technical specialties of the engineer training courses the factory currently provides. Course category "A - Common" means a training subject to provide every engineer with basic knowledge and technology indispensable for developing and manufacturing products in the factory. The training subjects also include six other categories, namely, "C - Electronic Circuits," "D - Control and Signal Processing," "E - System Engineering," "H - Telecommunications," "J Packaging and Construction," and "S - Software."

An experienced engineer at the department manager level is selected as training supervisor. The supervisor and staff establish (or cancel) training course subjects periodically and systematically as detailed in Section 3.3 below.

There are currently sixty mandatory courses, and elective subjects. A course lasts twelve hours on average, although it varies with the subject. A course coordinator is selected for each course. That coordinator determines the details as well as finding the lecturer of the course. That coordinator also decides pass or failure criteria based on attendance and test results. The course coordinator is selected from the experienced engineers in the factory, and the lecturer is usually an engineer also from the factory. 
Table 2 Technical Training Course Categories

\begin{tabular}{lll} 
Category Engineering specialty & Course & $\begin{array}{l}\text { Responsible } \\
\text { person }\end{array}$ \\
\hline
\end{tabular}

A Common Factory rules, cost and VEC, ISO9000/14000, quality/reliability, intellectual property, production processes

C Electronic circuits

Basics of electronic circuits, analog circuits, logic circuits, LSI

$\mathrm{X} 2$ design, power supply technology

D Control and signal
processing

Computer architecture, signal processing, voice signal $\mathrm{X} 1$ processing, image signal processing

\begin{tabular}{llll} 
E & SE & \multicolumn{1}{c}{$\begin{array}{l}\text { System proposal preparation, } \\
\text { telecommunication systems, } \\
\text { cellular systems }\end{array}$} & X4 \\
H & Telecommunications & $\begin{array}{l}\text { Communication protocols, } \\
\text { network configuration and } \\
\text { administration, radio } \\
\text { communication technology, } \\
\text { broadband ISDN, digital } \\
\text { transmission, LAN and computer } \\
\text { network, RAS design engineering }\end{array}$ & \\
J & & $\begin{array}{l}\text { Printed circuit board installation, } \\
\text { packaging, device evaluation }\end{array}$ & X6 \\
S & Packaging and & $\begin{array}{l}\text { Database, firmware, real-time OS, } \\
\text { programming, communication } \\
\text { software, software development } \\
\text { environment. }\end{array}$ & X7 \\
& Software & &
\end{tabular}

As described in Chapter 2, the trainees vary in their specialties and technical levels. Guidelines help trainees select courses based on their technical level. Table 3 lists an example of the courses. The starting class is for technical personnel with one or two year's experience after graduating from college or university; the middle class for experience of three to five years; and the upper class for experience of six or more years. $\mathrm{Ai}, \mathrm{Ci}, \mathrm{Di}, \ldots(\mathrm{i}=1-\mathrm{n})$ stand for the courses listed in Table 2 , for which different guidelines are provided for each specialty. The time period is set at 
approximately 80 hours for the starting class, 120 hours for the middle class, and 50 hours for the upper class, approximately 250 hours in total.

The trainees select their own specialty from those listed in Table 1 based on their duties, and register their applications to receive training courses that suit their own levels (starting, middle, or upper) according to the guidelines.

Table 3 Training Course Guidelines (Example)

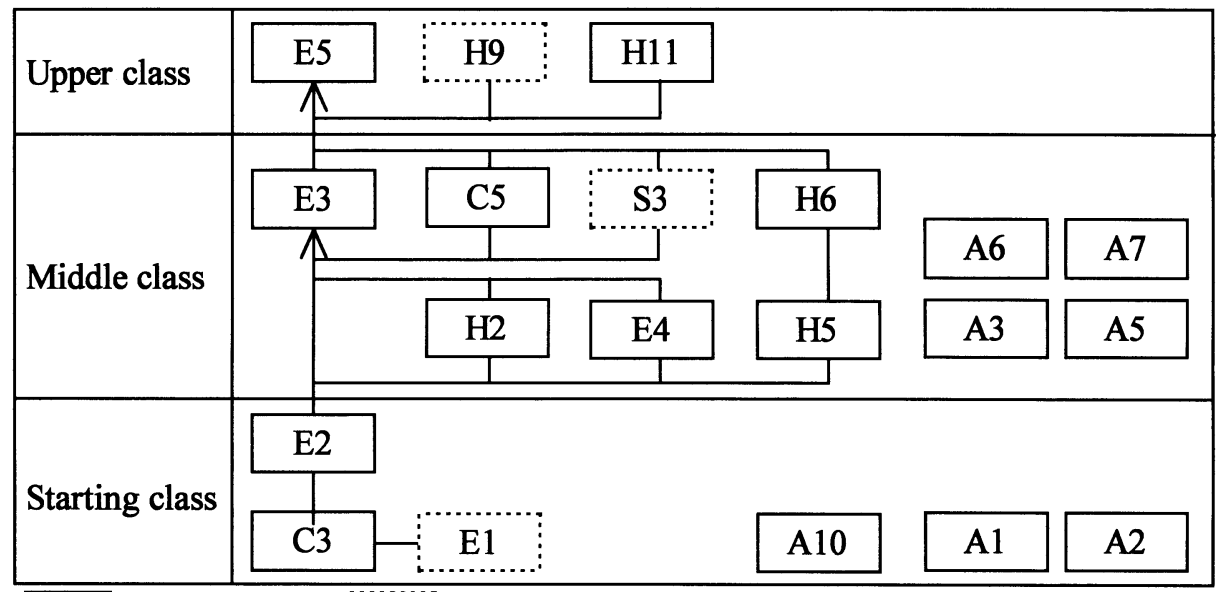

ए: Mandatory $: \cdots . . . . . .:$ : Selective

$\mathrm{Ai}, \mathrm{Ci}, \mathrm{Ei}$, etc. represent course titles.

\subsection{Individual Training History and Training Program}

The individual engineer's training course history is stored in a database. The database includes the individual's data such as personal name, section to which the individual belongs, title or position, and specialty as well as the list of the courses, which shows a training history (the date, pass or failure, passing level) and future training schedule.

\subsection{Technical Training Organization}

Figure 1 shows the organization to promote technical training. One term of technical training is six months, and is planned and promoted on the half-year basis. The training committee is composed of the factory's general manager as committee chair, and department managers. The committee reviews and determines technical training semiannually.

While discussing engineer training in training committee meetings, the factory's general manager asks committee members if the lecturers' or instructors' technical level is acceptable, not to mention the importance of canceling old, or establishing new, training subjects. Although it is a difficult decision to cancel a course because the lectures are invited from within the company - it is an important matter 
to be discussed. The committee coordinator asks the training committee members to review the matter.

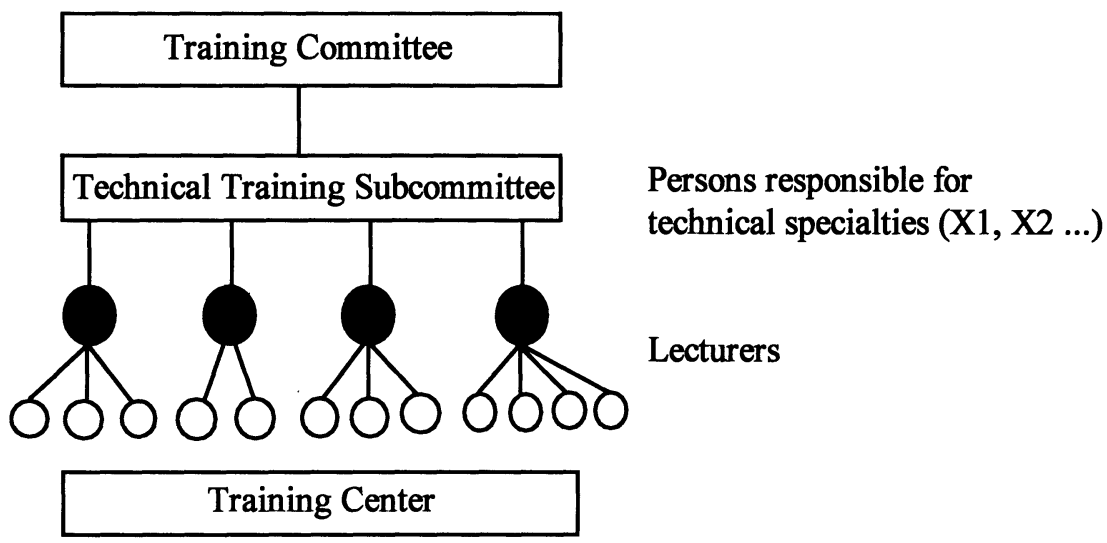

Figure 1 Engineer Training Organization

A technical training subcommittee is organized under the training committee. The members of the subcommittee are persons at the department manager level, responsible for each technical specialty mentioned in Section 3.1. The subcommittee also holds a meeting semiannually. The subcommittee reviews and determines the orientation of all the technical training courses, as well as the integration, cancelation and improvement of courses.

A training center is established as a formal organizational unit with a full-time person in charge to actually manage the engineer training activities.

The engineering training system is improved periodically and systematically to cope with changes and to prevent the training from becoming obsolete.

\section{Management System Utilizing the Intranet}

The intranet system established at the factory offers a home page for each shop to send out information. The training center provides various items of technical training information. The invitation to the technical training courses and the guidelines for the courses are provided on the intranet. The prospective trainees plan their own training programs and get an overview of the courses. Someone interested can apply for a course and the period from a pull-down list (a menu), then entering the applicant's name, unit, and employee number, and sending the file to the training center. The training center provides a data file for each individual. The data file summarizes the trainee's latest training program plan and history at the time of course application. Discussions are encouraged between the supervisor and the trainee to allow the trainees to acquire the basic technology necessary for performing their work.

Described above are the procedures for applying for a technical course. The courses are provided according to the program plan after the applicants are 
accepted. The time schedule of the course often changes according to the lecturer's needs. The course program on the training center's home page is useful for schedule changes. The course schedule is modified so that the trainee can check the course schedule beforehand and attend it on revised time.

The home page lists information on other courses to let engineers know about the availability of other training opportunities. An example is the guide to advanced technology lectures, featuring experts inside or outside the company providing engineers with a knowledge of telecommunications and peripheral technologies beyond their daily activities. The home page indicates the dates of such lectures, and outlines the past lectures. The home page also lists the invitations to technical training courses provided by other divisions of the company to enable our own engineers to attend computer-related courses.

\section{Conclusion}

This paper introduced the technical training provided by the factory, where we develop and manufacture telecommunication systems and equipment. The company's intranet efficiently manages invitations to technical training courses, manages applications, and posts course schedules. The most important matters in engineer training are the contents of the training courses and the establishment of a system to improve the courses to keep up with the technical innovations. The factory selects the coordinators of individual courses and the person responsible for a particular field to manage individual course coordinators to actively establish (or cancel) courses. Also, a technical training subcommittee meets periodically so that the persons responsible can orient and improve the technical training.

The authors expected that engineer training in a factory could be promoted more efficiently and effectively by quantitatively understanding the effects of technical training as well as the effects of establishing new courses, closing existing courses, integrating courses, etc. For this purpose, the authors are searching for a method of measuring quantitatively the effects of training by conducting pre- and post-training tests on the trainees, and applying the test results, that is, the difference before and after the course, to regression analysis ${ }^{1}$. However, no decisive or definite factors have been found so far, leaving the subject for further study.

The authors believe that it is more important to evaluate the training not in its effectiveness but in contribution to the company's activity. Engineer training is one of the activities for developing technical personnel who are able to implement the product development strategy established on the basis of the company's vision and policy. Thus, the extent or degree of engineering training being linked with the product development policy could be used as the evaluation standard.

In the reported training management system, the training results are not subjected to a labor evaluation. The evaluation should be linked with the job, and the technical training should be positioned as a fundamental for success. 


\section{References}

1. Yamamoto, H. et al., "Development and evaluation of computer-mediated education systems for customer engineers," Proceedings of IFIP WG3, 41993 205-214, NORTHHOLLAND

\section{Biography}

Yasuo Minai joined Hitachi, Ltd. after graduating from the Master of Arts course in Electrical Engineering, Yokohama National University, in 1970, and engaged in research of fiberoptic communications. Then, Minai engaged in equipment and system design engineering of fiberoptic image transmission at Hitachi's division headquarters and factories. He was appointed Manager of Human Resource Development Center, Telecommunications Division, in 1994, and is currently in the same position.

Masayuki Yamauchi joined Hitachi, Ltd. after graduating from the Master of Arts Course in Electrical Engineering, Ibaraki University, in 1974, and engaged in development of electronic switching system software at Totsuka Works. In 1983, Yamauchi was transferred to Human Resource Development Center where he engaged in training customers' engineering personnel on operation and maintenance of electronic switching systems. He then, as Senior Instructor, took responsibility for administration of employee training, and has been doing the same job to date.

Tsurayuki Kado currently holds the unique position of Chief Instructor at Hitachi, Ltd. He graduated from the Department of Science, Gakushuin University in 1964 and immediately started work with Hitachi. Since then, he has worked in the information systems field for thirty-four years. Ten of these years were spent as a designer of hardware and software, twelve as a systems engineer. Since 1986, he has been in charge of education and training. He is a Full Member of IFIP/WG3.4. 